WellBeing International

WBI Studies Repository

1986

\title{
Contribution to a Concept of Behavioral Abnormality in Farm Animals Under Confinement
}

\author{
U. A. Luescher \\ University of Guelph \\ J. F. Hurnik \\ University of Guelph
}

Follow this and additional works at: https://www.wellbeingintlstudiesrepository.org/acwp_faafp

Part of the Agribusiness Commons, Animal Studies Commons, and the Operations and Supply Chain Management Commons

\section{Recommended Citation}

Luescher, U.A., \& Hurnik, J.F. (1986). Contribution to a concept of behavioral abnormality in farm animals under confinement. In M.W. Fox \& L.D. Mickley (Eds.), Advances in animal welfare science 1986/87 (pp. 67-76). Washington, DC: The Humane Society of the United States.

This material is brought to you for free and open access by WellBeing International. It has been accepted for inclusion by an authorized administrator of the WBI Studies Repository. For more information, please contact wbisr-info@wellbeingintl.org.

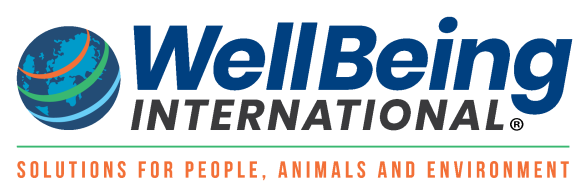




\title{
CONTRIBUTION TO A CONCEPT OF BEHAVIORAL ABNORMALITY IN FARM ANIMALS UNDER CONFINEMENT
}

\author{
U.A. Luescher ${ }^{1}$ and J.F. Hurnikg ${ }^{2}$
}

\section{Introduction}

Farm animals housed in close confinement often engage in activities that do not occur with animals maintained in traditional and more complex environments. Many of these activities consist of species-typical motor patterns directed towards unsuited or inappropriate objects, or performed as vacuum activities. For example, piglets fed from a trough from day 2 to day 21 after parturition display much nosing of penmates and ear sucking (DeBoer and Hurnik 1984). Similarly, confined veal calves in crates may lick their pelage excessively, or, when housed in groups, may suck the naval area of penmates; laying hens and broilers often engage in feather pecking and cannibalism. A list of reports in the literature concerning such behavior is given in Fox (1984). These behaviors are not adaptive, that is, they do not contribute to species-typical development, maintenance, or reproduction and they may even result in physical damage to the performer or its pen- or cagemates (Tschanz 1982). It is widely agreed that the occurrence of these abnormal behaviors is indicative of environmental inadequacy and animal suffering (Sambraus 1981; Fox 1984). Because abnormal behavior is believed to be an important criterion in evaluating animal housing systems and management practices, there is a need for a general concept of behavioral abnormality in farm animals that would facilitate making judgments about the acceptability of given production systems, and to predict effects of environmental changes on animal welfare (Duncan 1983).

This paper contributes to the development of a concept of behavioral abnormality by comparing the situation of animals in an artificial environment to an experimental learning situation. The concept is based on behavioristic theory developed by Seligman (1970) and Staddon and Simmelhag (1971). The concept provides a novel perspective of behavioral normality and abnormality. 
To account for the fact that some stimulus-response associations are more easily established than others by animals in learning experiments, Seligman (1970) offered the so-called concept of "preparedness." He hypothetically postulated an ease-of-learning continuum. On one end were associations phylogenetically predisposed with high probability, which the author called "prepared" associations. On the other end were associations predisposed with low probability, which he called "contraprepared" associations. Between the two extremes is a middle range of so-called unprepared associations (those traditionally studied in learning laboratories).

Staddon and Simmelhag (1971) developed an entirely new concept that relates the nature of learning processes to evolutionary theory. They regard learning:

... as the outcome of two independent processes: a process of variation that generates either phenotypes in the case of evolution, or behavior in the case of learning; and a process of selection that acts within the limits set by the first process.

Thus, learning is considered to be in part a selection process analogous to, but separate from, phylogenetic selection. The ontogenetic selection process is controlled by what they call principles of reinforcement. They claim that "reinforcement acts only to eliminate behaviors that are less directly correlated with reinforcement than others."

The Staddon/Simmelhag theory takes into consideration the effect of genetics on behavior and on learning, and thus bridges a serious conflict between behaviorists and ethologists.

The present concept, developed on the basis of these theories, provides insight into the nature of environmentally-induced abnormal behavior in farm animals, and defines conditions required for its prevention. According to Hurnik et al. (1985), animal well-being can be defined as "a state or condition of physical and psychological harmony between the organism and its surroundings." Provision of appropriate conditions (those allowing normal behavior) is therefore considered an essential prerequisite for animal well-being.

\section{Phylogenetic Adaptation}

The process of phylogenetic adaptation results from an interplay between mutation increasing the range of genetically determined characteristics and the environment selecting those characteristics that give their carriers some advantage over noncarriers. Phylogenetic adaptation provides a defined range of behaviors in which an animal is able to engage.

The behavioral repertoire of a species often is subdivided into functional systems, such as ingestive, sexual, or eliminative behavior. Each functional system contains subcategories of behaviors, which will be called functional units of behavior. Behaviors within a functional unit are characterized by basically similar motor patterns and similar functions, and presumably are promoted by similar motivational factors. 
The range of behaviors in each functional unit is determined by phylogeny. For example, the functional system of ingestive behavior includes the functional units of eating and drinking. The functional unit of eating may embrace such behaviors as eating grain, grazing grass, or chewing roots. Strong selection pressure on a functional unit of behavior during phylogeny results in a high degree of fixation and leaves little room for ontogenetic shaping. Weak selection pressure, in contrast, results in a broad range of possible behaviors within a functional unit, and leaves much room for learning. Behaviors with a high degree of fixation often are called instinctive; those with very low degree of fixation, learned.

Performance of a given behavior in general is preceded by the establishment of a stimulus-response association. When an animal is motivated, e.g., to sleep or to groom, it will search for appropriate releasing stimuli, such as a suitable shelter or an object for scratching on, according to genetically predisposed associations between sleeping and shelter, or grooming and a rough vertical surface. Such an association between action pattern and releasing stimulus thus is an integral part of a behavior. Therefore, each functional unit of behavior contains a phylogenetically determined range of stimulusresponse associations.

Like Seligman's (1970) notion of "preparedness," the present concept suggests that the stimulus-response associations (and thus the behaviors) in a given functional unit are not predisposed in the genotype of an animal to be established with equal likelihood. Rather, they are characterized by their differential probability of being established. Phylogeny not only determines the range of possible stimulus-response associations contained within each functional unit of behavior, but also the probability of the associations relative to each other. As a result of phylogenetic adaptation, the stimulus-response associations that are most successful and presumably most rewarding in a

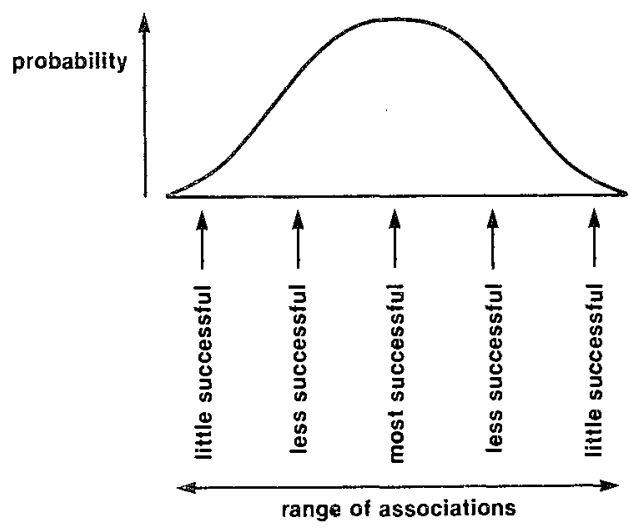

Figure 1. Genetically predisposed probability distribution for stimulus-response associations contained in one functional unit of behavior. 
species' natural environment are generally predisposed with highest relative probability. This situation can be represented, for example, by a normal probability distribution as in figure 1 .

The normal distribution has been chosen to represent real distributions for the sake of simplicity. On the abscissa, stimulus-response associations contained within one functional unit of behavior are arranged. For example, within the functional unit of roosting in hens, associations may range from between roosting and a thin twig to roosting and a very thick branch.

Different stimuli for associations of a functional unit, such as elevated perch, wooden slats, and wire floor for roosting in hens; or roots, straw, and tails of penmates for eating in pigs, usually vary with regard to several or many of their characteristics. To arrange associations to such stimuli along one axis is a simplification. As a matter of fact, they should be arranged along several independent axes, resulting in a multidimensional diagram.

The ordinate is a scale for the relative probabilities for the various associations within a functional unit. For instance, the association between roosting and a branch of a certain diameter (e.g., 2 inches), is predisposed in a hen's genotype with higher probability (and thus lies closer to the median of the distribution), than is the association between roosting and either a very thin or a very thick branch. Or the association between eating and roots is predisposed in the genotype of a pig with higher probability than the one between eating and straw, or eating and other pigs' tails.

Accordingly, in an artificial environment, provision of stimuli similar to the ones preferably responded to in the natural environment should facilitate the establishment of stimulus-response associations. Further, responses to these stimuli should be more probable than responses to less natural stimuli. Mees and Metz (1983) have obtained results that support this hypothesis (figure 2). In their experiment, young calves were given milk from pails with or without rubber teats. Frequency of sucking was higher in the group that had pails with teats. In both groups, if the pails were removed when empty, calves sucked on objects or ears of penmates. If empty pails were not removed, calves continued to suck on them. Frequency of overall sucking (including sucking on pails as well as other objects) was higher in the group that had pails with teats than in the group that had pails without teats. If the pails were removed, frequency of sucking dropped in both groups to below the levels exhibited by either group when the pails were present. This indicates a higher probability for sucking on a rubber teat than for sucking on a plain pail or even non-food related objects.

\section{Ontogenetic Adaptation}

In analogy to Staddon and Simmelhag (1971), behavioral adaptation during ontogeny can be defined as environmentally-controlled selection from a range of stimulus-response associations. The range as well as the probabilities of these associations are determined by phylogenetic processes, as explained earlier. In a given environment, some associations are more "directly corre- 


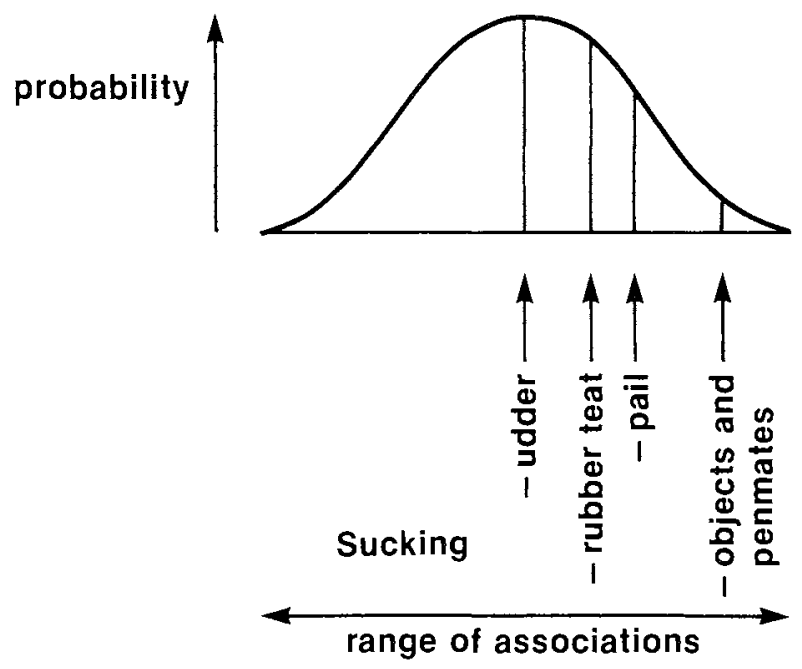

Figure 2. Functional unit of sucking in calves: Genetically predisposed probability distribution for stimulus-response associations.

lated with reinforcement than others" (Staddon and Simmelhag 1971), because the behaviors resulting from these association are most successful. The probability of these associations thus increases, while the probability of other associations is reduced.

This also applies to the natural environment of a species. In the natural environment, associations that are genetically predisposed with highest relative probability generally are reinforced the most. The genetically predisposed distribution of association probability and the phenotypic one resulting from ontogenetic adaptation of a given species in its natural environment are illustrated in figure 3 for eating in pigs. The medians of the two curves coincide, but their variances differ.

When an environment is provided that does not contain the natural stimuli appropriate to associations near the median of the probability distribution, these associations cannot then be behaviorally manifested, and thus are no longer reinforced. Other associations, for which stimuli are provided, are reinforced since the behaviors resulting from them become relatively successful (figure 4). If these associations lay sufficiently close to the median of the probability distribution, reinforcement of these associations will effectively suppress others, and the animal is considered to have adapted to the new situation.

As the deviation of the environment from natural becomes more pronounced, the genetically predisposed probability of the associations reinforced in the given environment is low, and the resulting behaviors are less rewarding. In accordance with Staddon and Simmelhag (1971), reinforcement of some stimulus-response association reduces the probability of those that 


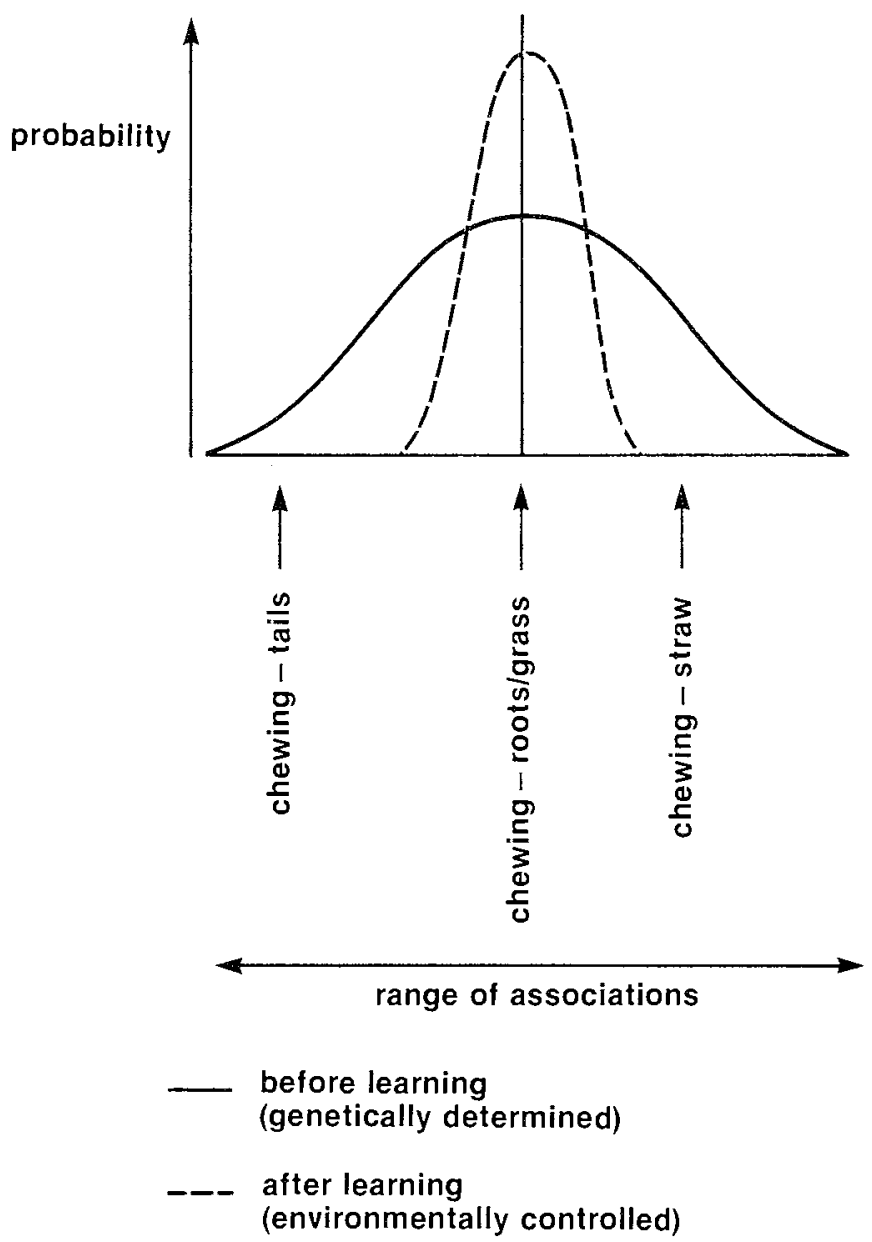

Figure 3. Functional unit of eating in pigs: Phenotypic probability distribution for stimulus-response associations in the natural environment, as compared to the genetically predisposed distribution. 

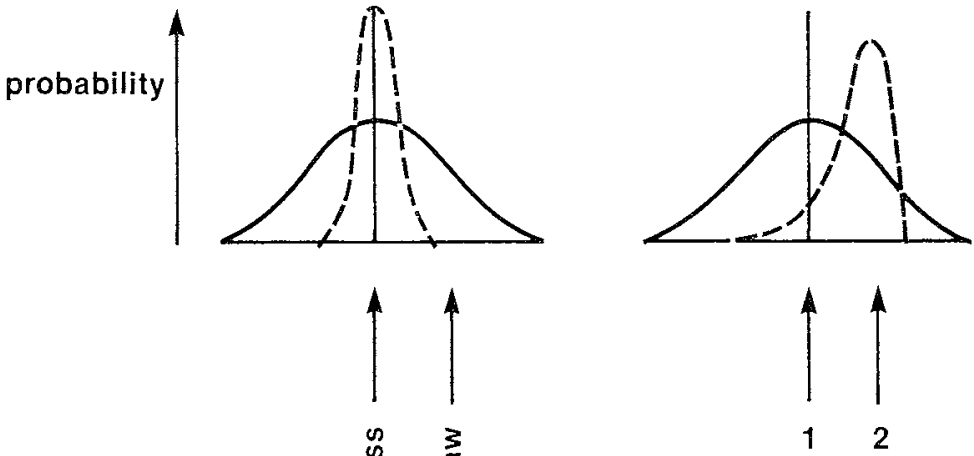

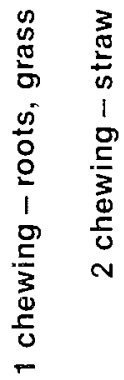

a

b

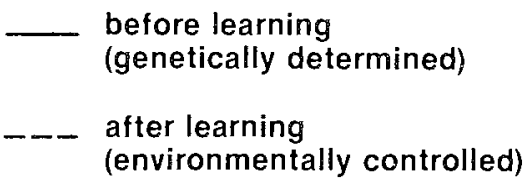

Figure 4. Functional unit of eating in pigs: Phenotypic probability distribution for stimulus-response associations in a semi-natural environment, as compared to the genetically predisposed distribution. 
are not reinforced. Weak reinforcement of an association thus only slightly reduces the probability of non-reinforced associations. This situation is schematically illustrated in figure 5 .

If the environment reinforces only stimulus-response associations predisposed with very low probability, the resulting behaviors very likely provide little reward. Therefore, the environment is not effective in selectively reinforcing certain associations and suppressing others. Thus, the resulting probability distribution of associations very strongly resembles the genetically predisposed one. In such a situation motor patterns similar to those characteristically displayed towards appropriate stimuli are performed even though no such stimuli are present, i.e., the animal engages in vacuum activities which often become stereotyped.
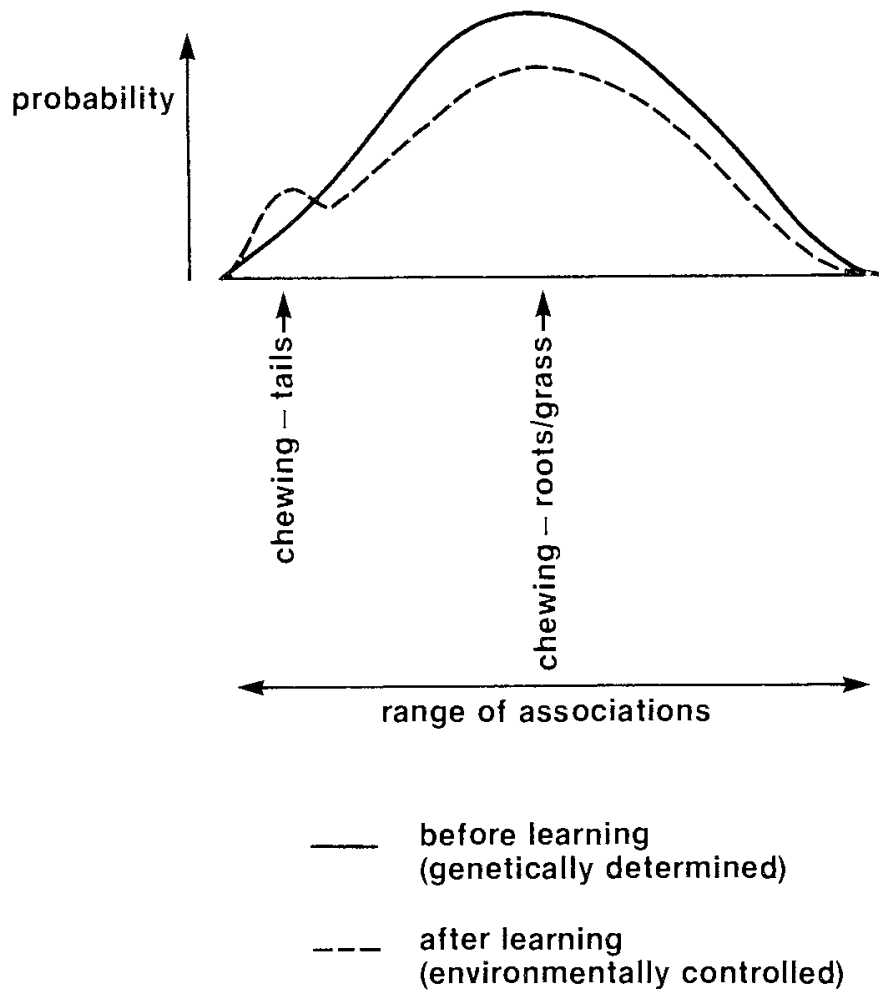

Figure 5. Functional unit of eating in pigs: Phenotypic probability distribution for stimulusresponse associations in an environment which strongly deviates from natural, as compared to the genetically predisposed distribution. 
The question, under what circumstances some functional units (for which only highly inappropriate stimuli are provided) can be replaced by others (for which there are more appropriate stimuli) is a complex issue which is not further addressed in this paper. It is maintained, however, that in most cases such replacement seems not possible, and that at any point in time an animal engages in some behavior of a functional unit with given probability.

\section{Normal and Abnormal Behavior}

The proposed concept provides an opportunity to define normal and abnormal behavior in statistical terms.

Behavior can be considered normal if its underlying stimulus-response association is genetically predisposed with sufficiently high probability in relation to others within the same functional unit of behavior, i.e., if it lies within certain limits of the genetically determined probability distribution.

In contrast,

Behavior can be considered abnormal if the underlying association is genetically predisposed with low probability, i.e., if it lies outside these limits (figure 6).

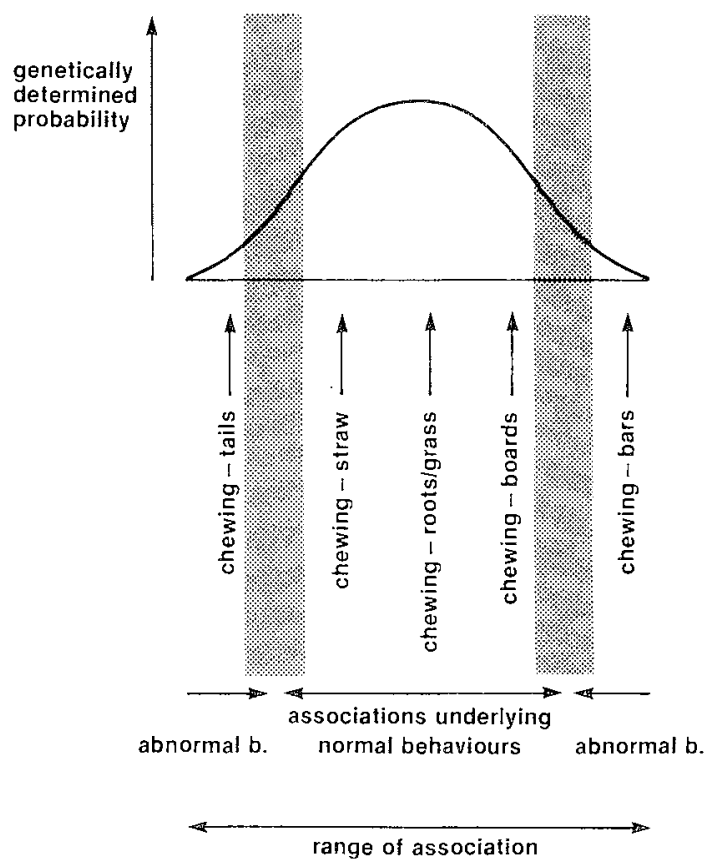

Figure 6. Functional unit of eating in pigs: Normal and abnormal behavior as defined statistically with reference to the genetically predisposed probability distribution for stimulus-response associations. 


\section{Conclusions}

(1) Behavior generally is characterized by a motor pattern and its relation to the environment. Thus, a stimulus-response association is a determinative characteristic of any behavior related to stimuli in the environment.

(2) Stimulus-response associations are predisposed with a genetically determined probability, defined in relation to the probabilities of other associations within the same functional unit of behavior.

(3) The genetically predisposed distribution of association probabilities is determined by natural selection and domestication and can to some extent be influenced by selective breeding.

(4) Behavior resulting from stimulus-response associations predisposed with low relative probability (i.e., behavior directed toward inappropriate objects) is always abnormal, even if its motor pattern very strongly resembles that resulting from an association predisposed with high probability (i.e., behavior directed toward appropriate objects).

(5) Living conditions for farm animals are appropriate only if the environment reinforces the establishment of stimulus-response associations that are predisposed with sufficient probability.

(6) Ontogenetic adaptation (learning) results in a phenotypical probability distribution of stimulus response associations that deviates from the genetically predisposed distribution.

\section{Endnotes}

${ }^{1}$ Assistant Professor, Dept. of Clinical Studies, University of Guelph, Guelph, Ontario, Canada, N1G 2W1. Address to which reprint requests sbould be sent.

2 Professor, Dept. of Animal and Poultry Science, University of Guelph.

\section{References}

DeBoer, S and Hurnik, JF. 1984. Automatic device for group rearing of piglets: feeding variations. 34 th Annual Conference, C.S.A.S., Aug. 19-22, Winnipeg, Manitoba.

Duncan, IJ. 1983. Assessing the effect of housing on welfare. In: Baxter, SH, Baxter, MR, and MacCormack, JA. eds. Farm Animal Housing and Welfare. Dordrecht, The Netherlands: Martinus Nijhoff.

Fox, MW. 1984. Farm Animals: Husbandry, Bebavior and Veterinary Practice. Baltimore, MD, USA: University Park Press.

Hurnik, JF, Webster, AB and Siegel, BP. 1985. Dictionary of Farm Animal Bebavior. University of Guelph.

Mees, AM and Metz, JH. 1983 Saugverhalten von KalbernBedurfnis und Befriedigung bei verschiedenen Trankesystemen. Tagung Dt. vet. med. Ges. e.v., Fachgruppe Verhaltensforschung, 16.-19.11.1983, Freiburg, i.Br.

Sambraus, HH. 1981. Abnormal behavior as an indicator of immaterial suffering. Int. J.Stud. Anim. Prob. 2: 245-48.

Seligman, ME. 1970. On the generality of laws of learning. Psych. Rev. 77: 406-18.

Staddon, JE and Simmelhag, VL. 1971. The "superstition" experiment: A reexamination of its implications for the principles of adaptive behavior. Psych. Rev. 78:3-43.

Tschanz, B. 1982. Verhalten, Bedarfsdeckung und Schadenvermeidung bei Tieren. Tagung Nutztierkommission Schwiezer Tierschutz, Int. Ges. fur Nutztierhaltung, 23.4. 1982, Bern. 